\title{
Tacrolimus Ointment for Treatment of Vernal keratoconjunctivitis
}

\author{
Dr. Jitendra kumar ${ }^{1}$, Dr. Shweta dwivedi ${ }^{2}$, Dr.Amit Verma ${ }^{3}$, \\ Dr.Arun Kumar pathak ${ }^{4}$. \\ ${ }^{1,2,3,4}$ (Department Of Ophthalmology, M.L.B. Medical college/Bundelkhand University, India)
}

\begin{abstract}
This study was conducted to evaluate efficacy and safety of topical $0.1 \%$ tacrolimus eye ointment for treatment of refractory vernal keratoconjunctivitis (VKC) and included 60 eyes of 30 patients, who had active symptomatic disease despite conventional medications including topical steroids. Mean age of patients was was $22.9 \pm 3.6$ years and mean duration of VKC was $61.7 \pm 4.3$ months. After starting tacrolimus eye ointment ,patients were followed and was found that all symptoms including itching, redness, foreign body sensation improved after the treatment; itching was the first symptom to show dramatic relief. In addition, there was improvement in objective signs including Lid thickening,Conjunctival hyperemia Papillae,Trantas dots,Superficial punctuate keratopathy; conjunctival hyperaemia was the first sign to show improvement. There was statistically significant improvement in symptoms of itching redness, foreign body sensation $(P<0.001)$. Statistically significant improvement was also observed in clinical signs of Lid thickening,Conjunctival hyperemia Papillae,Trantas dots,Superficial punctuate keratopathy $(P<0.001)$. The ointment form of tacrolimus was well tolerated. None of the patients developed elevation of intraocular pressure, cataract, or infectious keratitis. Topical $0.1 \%$ tacrolimus eye ointment seemed to be a safe and effective treatment for steroid-resistant refractory VKC; however, long-term use was needed to control the disease.
\end{abstract}

Keywords: Vernal keratoconjunctivitis, ointment, tacrolimus, papillae, steroid resistant.

\section{Introduction}

Vernal keratoconjunctivitis (VKC) is a bilateral, chronic inflammation of the conjunctiva that predominantly affects children between 3 and 16 years of age. It usually resolves at puberty, but can continue into adulthood. Although the name vernal suggests a seasonal, springtime occurrence, this allergic condition frequently persists throughout the year and usually increases in intensity in warmer weather[1,2] Patients with VKC experience significant morbidity[3]. Symptoms include intense itching, tearing, mucous secretions, and photophobia[4] Common conjunctival signs of VKC are hyperemia, papillary hypertrophy, giant papillae, discharge, and trantas dots[5].

Currently available drugs to treat VKC include antihistamines, mast-cell stabilizers, corticosteroids, and immunomodulators. VKC requires long-term treatment in many cases. Topical steroids are the mainstay of treatment for moderate to severe forms of VKC. Steroids, however, cannot be administered for a long period. Injudicious and prolonged use of topical steroids may lead to glaucoma, cataract, and secondary infections. The risk of steroid-induced ocular complications in VKC is particularly high in children who are the most commonly affected age group[23] .

Recently, immunomodulatory agents have been used to avoid steroid-related complications. Tacrolimus has an immunomodulatory and anti-inflammatory activity. Tacrolimus suppresses Th2 lymphocyte activation, T helper cell-mediated B-cell proliferation, and formation of cytokines[24].

It is isolated from Streptomyces tsukubaensi.[6] It binds to FK506-binding proteins in T-lymphocytes and inhibits calcineurin activity. Calcineurin inhibition suppresses dephosphorylation of the nuclear factor of activated T-cells and its transfer into the nucleus, which suppresses the formation of T-helper (Th) 1 (interleukin [IL]-2, interferon $\gamma$ ) and Th2 cytokines (IL-4, IL-5) [7] . Tacrolimus also inhibits histamine release from mast cells, which is thought to alleviate allergic symptoms[8]. Tacrolimus is up to 100 times more potent than cyclosporine $[\mathbf{9 , 1 0 , 1 1 ]}$. Tacrolimus ointment is used widely for the treatment of atopic dermatitis. Topical tacrolimus $(0.02-0.1 \%)$ has also been used to treat giant papillary conjunctivitis, atopic keratoconjunctivitis (AKC), and VKC[12-18] with good results. Furthermore, a tacrolimus $0.1 \%$ ophthalmic suspension has been used for the treatment of AKC and VKC with only 4 weeks of follow-up[18]

The purpose of this study was to evaluate the long-term clinical outcomes of tacrolimus ointment as a treatment for refractory VKC. 


\section{Materials And Methods}

Prospective study was conducted at the OPD of Department Of Ophthalmology at M.L.B Medical College, Jhansi. The study followed 60 eyes from 30 patients with active VKC refractory to conventional treatment.. Patients were recruited from ophthalmology department after written informed consent was obtained.

\section{Inclusion criteria}

All study participants with active disease who were steroid dependent, despite treatment with cyclosporine or conventional treatments such as antihistamines, mast-cell stabilizers, topical nonsteroidal antiinflammatory drugs, and topical steroids.

\section{criteria}

Patients who had coexisting conjunctival disorders, chemical injury, Stevens-Johnson syndrome, corneal diseases, uveitis, ocular infections, and contact lens use, a history of systemic nonsteroidal antiinflammatory or immunosuppressive drug use, and ocular surgery in the previous 3 months.

VKC was diagnosed by :

(1) symptoms (chronic, bilateral itching, redness); and

(2) signs (trantas dots, papillae on the upper tarsal conjunctiva, corneal erosions).

Complete ophthalmic examinations was performed, including best spectacle-corrected visual acuity (BSCVA), slit-lamp biomicroscopy, fluorescein staining, fundoscopy, and tonometry. Study participants discontinued all medications, 1-week before beginning treatment. All participants were instructed to apply tacrolimus $0.1 \%$ ointment to the inferior conjunctival fornix of each eye. The dose for severe AKC was once daily for 1-month followed by a taper to every other day for 1-week; then twice a week for 1-week; then once a week. The dose for moderate AKC was once every other day for 1-month followed by a taper to twice a week for 1-week; then once a week. The dose for mild AKC was twice a week for the $1^{\text {st }}$ month and then once a week. During treatment, patients returned for evaluation after 1-week, 4 weeks, 6 weeks, and then every 6 months. The primary efficacy endpoint was change from baseline with topical tacrolimus treatment. Main outcomes were graded by severity of signs[Table 1] and symptoms[Table 2] at baseline (before treatment) and at each visit using a 4 -grade scale $(0=$ no symptoms; $1=$ mild; $2=$ moderate; $3=$ severe $)$ Signs included conjunctival hyperemia, papillary hypertrophy of the superior tarsal conjunctiva, trantas dots, and superficial punctuate keratopathy.

Table 1 : Grading Scale Of Clinical Signs

\begin{tabular}{|l|l|l|}
\hline \multicolumn{1}{|c|}{ Sign } & Score & \multicolumn{1}{c|}{ Definition } \\
\hline $\begin{array}{l}\text { Conjunctival } \\
\text { Hyperemia }\end{array}$ & 3 & $\begin{array}{l}\text { Diffuse Dilated Blood Vessels Over } \\
\text { Entire Bulbar Conjunctiva }\end{array}$ \\
\hline & 2 & Dilatation Of Many Vessels \\
\hline & 1 & Dilatation Of Few Vessels \\
\hline & 0 & None \\
\hline Papillae & 3 & Papillae Size $>0.3 \mathrm{~mm}$ \\
\hline & 2 & Papillae Size $0.2-0.3 \mathrm{~mm}$ \\
\hline & 1 & Papillae Size $<0.2 \mathrm{~mm}$ \\
\hline ITrantas Dots & 0 & None \\
\hline & 3 & 6 Dots \\
\hline & 2 & 4-6 Dots \\
\hline & 1 & 1-3 Dots \\
\hline $\begin{array}{l}\text { Superficial Punctuate } \\
\text { Keratopathy }\end{array}$ & 3 & None \\
\hline & 2 & Total Corneal Surface \\
\hline & 1 & More Than Half Corneal Surface \\
\hline & 0 & Less Than Half Corneal Surface \\
\hline
\end{tabular}

Symptoms included itching, redness, foreign body sensation. 
Table 2 : Grading Scale Of Clinical Symptoms

\begin{tabular}{|l|l|l|}
\hline \multicolumn{1}{|c|}{ Symptom } & Score & \multicolumn{1}{c|}{ Severity } \\
\hline Itching & 3 & Severe \\
\hline & 2 & Moderate \\
\hline & 1 & Mild \\
\hline & 0 & No Symptom \\
\hline Redness & 3 & Severe \\
\hline & 2 & Moderate \\
\hline & 1 & Mild \\
\hline & 0 & No Symptom \\
\hline Foreign Body Sensation & 3 & Severe \\
\hline & 2 & Moderate \\
\hline & 1 & Mild \\
\hline & 0 & No Symptom \\
\hline
\end{tabular}

All data were analyzed using SPSS. Analysis of variance and the Wilcoxon test were to analyze changes in the mean scores of signs and symptoms following treatment with topical tacrolimus $0.1 \%$ ointment. $P \leq 0.05$ was considered statistically significant.

\section{Results}

Sixty eyes from 30 patients (26males) with bilateral VKC (mean \pm standard deviation duration; $61.7 \pm 4.3$ months were included in this study. The mean age was $22.9 \pm 3.6$ years[Table 3]. All patients had active, perennial, symptomatic disease that was refractory to medication, including antihistamines, mast-cell stabilizers, topical cyclosporine, and steroids.

Table 3: Characteristics Of Adult Patients With VKC

\begin{tabular}{|l|l|l|l|l|}
\hline S. No. & Age & Gender & VKC duration(months) & Follow-up (months) \\
\hline 1 & M & 19 & 24 & 26 \\
\hline 2 & F & 26 & 78 & 28 \\
\hline 3 & M & 27 & 96 & 26 \\
\hline 4 & M & 31 & 180 & 28 \\
\hline 5 & M & 21 & 60 & 24 \\
\hline 6 & M & 28 & 120 & 30 \\
\hline 7 & M & 9 & 12 & 36 \\
\hline 8 & M & 23 & 36 & 20 \\
\hline 9 & M & 16 & 48 & 22 \\
\hline 10 & F & 22 & 60 & 26 \\
\hline 11 & M & 28 & 84 & 24 \\
\hline 12 & M & 24 & 48 & 30 \\
\hline 13 & M & 31 & 132 & 26 \\
\hline 14 & M & 15 & 12 & 24 \\
\hline 15 & M & 26 & 96 & 26 \\
\hline 16 & M & 15 & 24 & 25 \\
\hline 17 & M & 20 & 48 & 23 \\
\hline 18 & M & 21 & 60 & 20 \\
\hline 19 & F & 25 & 84 & 28 \\
\hline 20 & M & 20 & 48 & 30 \\
\hline 21 & M & 22 & 66 & 23 \\
\hline 22 & M & 24 & 36 & 21 \\
\hline 23 & M & 21 & 40 & 22 \\
\hline 24 & M & 26 & 60 & 24 \\
\hline 25 & M & 28 & 48 & 26 \\
\hline 26 & M & 17 & 12 & 22 \\
\hline 27 & M & 27 & 36 & 28 \\
\hline 28 & M & 23 & 84 & 28 \\
\hline 29 & F & 25 & 48 & 24 \\
\hline 30 & M & 26 & 72 & \\
\hline & & & & \\
\hline
\end{tabular}

Itching was the most prominent symptom (26/30); other complaints included redness and foreign body sensation. All eyes had lid thickening, conjunctival hyperemia, and papillary conjunctivitis, and $10 \%$ of patients 
had a history of atopy. After starting treatment with tacrolimus $0.1 \%$ ointment, patients were followed for a mean duration of $25.7 \pm 0.8$ months.

There were significant improvements in the clinical signs and symptoms of disease after starting treatment with tacrolimus. Itching was the first symptom to decrease. At baseline, 26 of 30 patients complained of itching (21 severe, 5 moderate), however, after 1-week of treatment, all patients improved[Table 4]. After 6 weeks, all patients achieved complete resolution of their symptoms of itching[Fig $\mathbf{1 a} / \mathbf{1} \mathbf{b} / \mathbf{1 c}]$.At the end of the follow-up period, all patients remained asymptomatic but continued to apply topical tacrolimus ointment. No additional medications, such as mast cell stabilizers, topical cyclosporine, or steroids, were required to provide additional relief.

Table 4: Mean score of symptoms in patients with Vernal-Keratoconjunctivitis before and after treatment with topical tacrolimus $0.1 \%$ ointment.

\begin{tabular}{|l|l|l|l|l|l|}
\hline Symptom & Before & 1 week & 6 weeks & Final follow-up & p \\
\hline Itching & $2.11 \pm 0.33$ & $1.30 \pm 0.40$ & $1.12 \pm 0.33$ & $0.22 \pm 0.32$ & $<0.001$ \\
\hline Redness & $2.15 \pm 0.35$ & $1.22 \pm 0.33$ & $0.15 \pm 0.30$ & $0.10 \pm 0.33$ & $<0.001$ \\
\hline Foreign body sensation & $2.05 \pm 0.40$ & $1.25 \pm 0.37$ & $0.25 \pm 0.20$ & $0.11 \pm 0.22$ & $<0.001$ \\
\hline
\end{tabular}

$\mathrm{p}<0.05$ is statistically significant

Figure 1a/1b/1c : Showing Resolution Of Symptoms At The End Of Follow Up

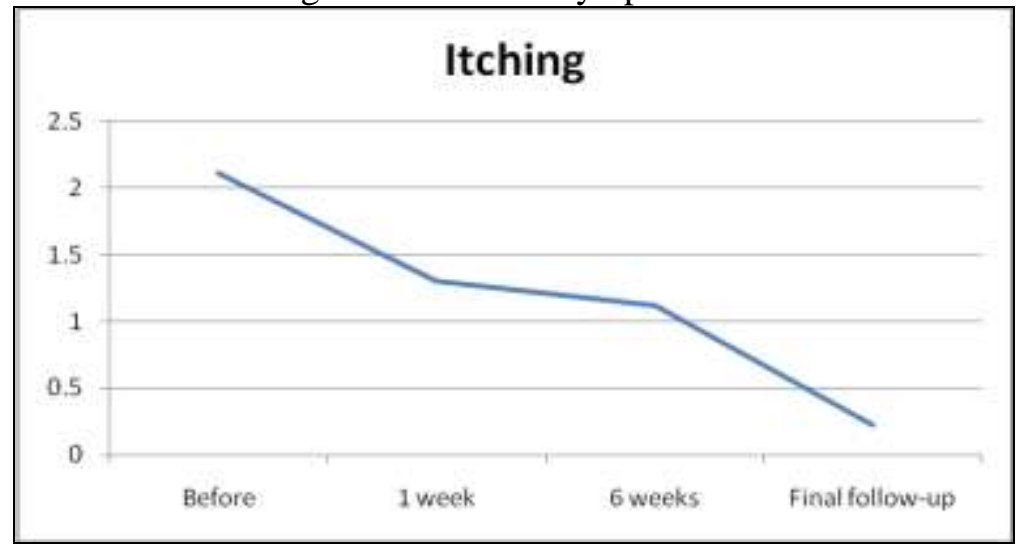

figure 1a

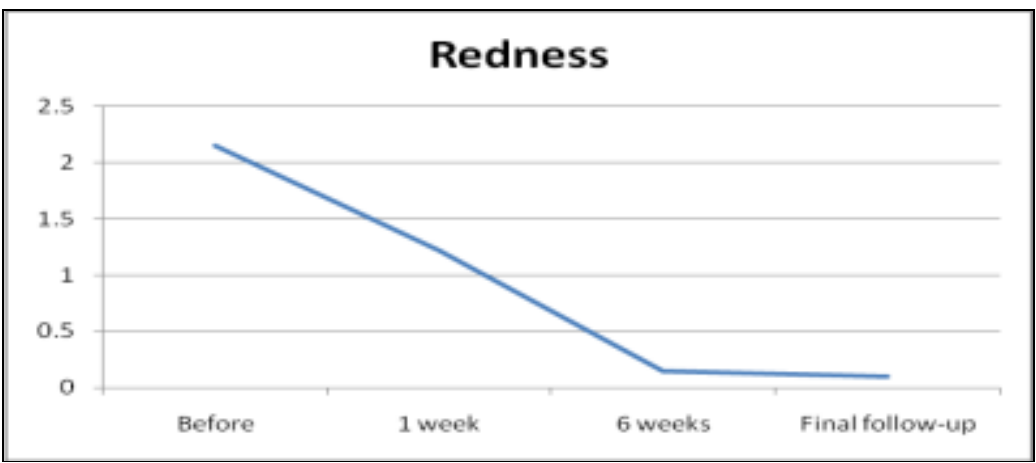

figure $1 b$ 


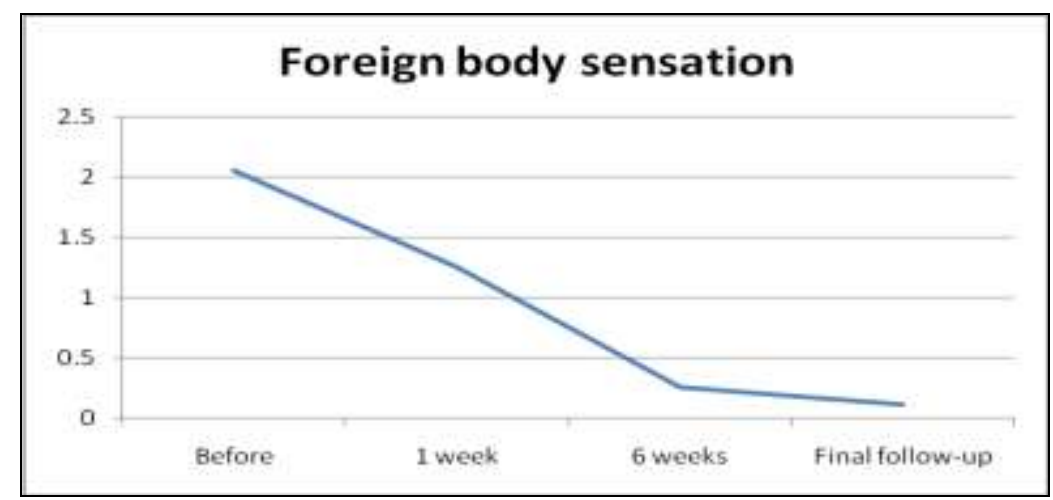

Figure 1c

Prior to treatment, conjunctival hyperemia was present in 57 eyes (47 severe, 6 moderate, 4 mild). Conjunctival hyperemia was completely resolved in 55/60 eyes, 6 weeks after the initiation of treatment[Fig 3].Improvement in conjunctival papillary hypertrophy was seen in 30 eyes, 6 weeks after starting treatment. After 3 months, 12 patients had only mild papillary hypertrophy. Thirty-two eyes that had moderate or severe lid thickening at baseline showed improvements in clinical signs, 6 weeks after starting treatment[Table 5]. All patients (30/60 eyes) with moderate or severe corneal punctate epithelial erosions showed improvement 8 weeks after starting treatment. All these eyes had mild corneal punctate epithelial erosions after 2 months of treatment which completely resolved at the last follow-up visit.[Fig $\mathbf{2 a} / \mathbf{2 b} / \mathbf{2} \mathbf{c} / \mathbf{2 d} / \mathbf{2 e}$ ].

Table 5: Mean Score Of Signs In Patients With Vernal-Keratoconjunctivitis Before And After Treatment With Topical $0.1 \%$ Tacrolimus Ointment.

\begin{tabular}{|l|l|l|l|l|l|}
\hline Sign & Before & $\mathbf{1}$ week & $\mathbf{6}$ weeks & $\begin{array}{l}\text { Final follow- } \\
\text { up }\end{array}$ & p \\
\hline Lid thickening & $2.20 \pm 0.43$ & $1.23 \pm 0.33$ & $1.06 \pm 0.30$ & $0.24 \pm 0.40$ & $<0.001$ \\
\hline Conjunctival hyperemia & $2.30 \pm 0.50$ & $1.70 \pm 0.46$ & $0.95 \pm 0.30$ & $0.32 \pm 0.38$ & $<0.001$ \\
\hline Papillae punctuate & $2.05 \pm 0.60$ & $1.28 \pm 0.43$ & $0.82 \pm 0.33$ & $0.21 \pm 0.24$ & $<0.001$ \\
\hline Trantas dots & $2.10 \pm 0.46$ & $1.12 \pm 0.38$ & $0.71 \pm 0.23$ & $0.16 \pm 0.18$ & $<0.001$ \\
\hline $\begin{array}{l}\text { Superficial } \\
\text { keratopathy }\end{array}$ & $1.16 \pm 0.22$ & $0.90 \pm 0.42$ & $0.12 \pm 0.22$ & $<0.001$ \\
\hline
\end{tabular}

$\mathrm{p}<0.05$ is statistically significant

Figure 2a/2b/2c/2d/2e : Showing Resolution Of Signs At The End Of Follow Up

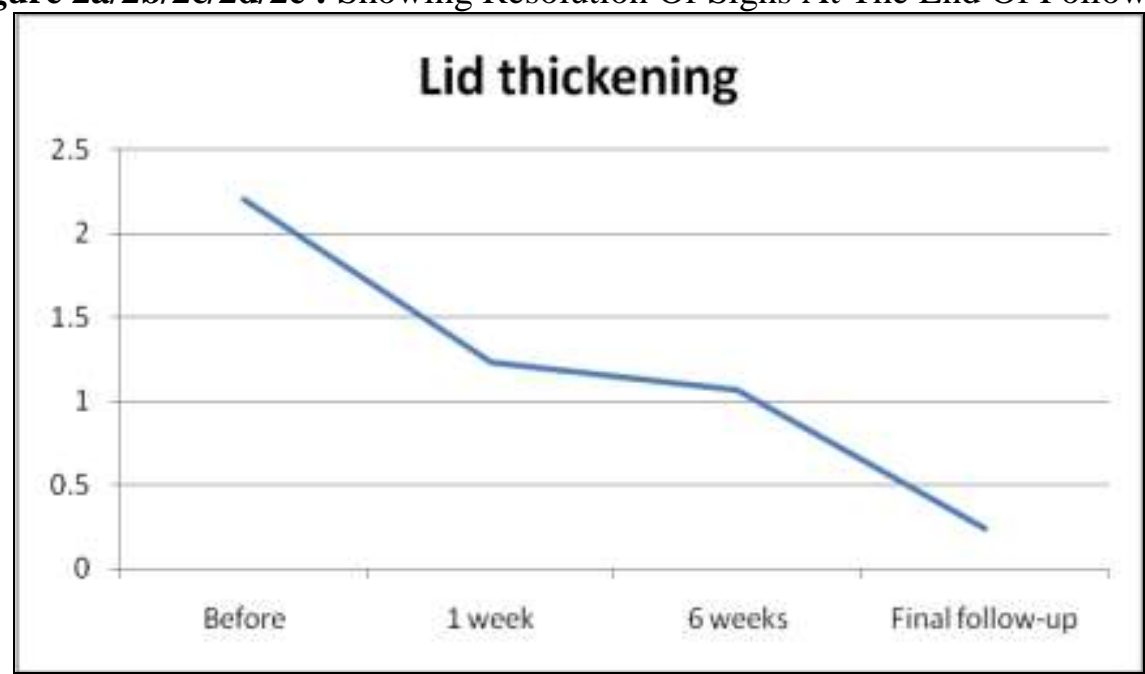

Figure 2a 

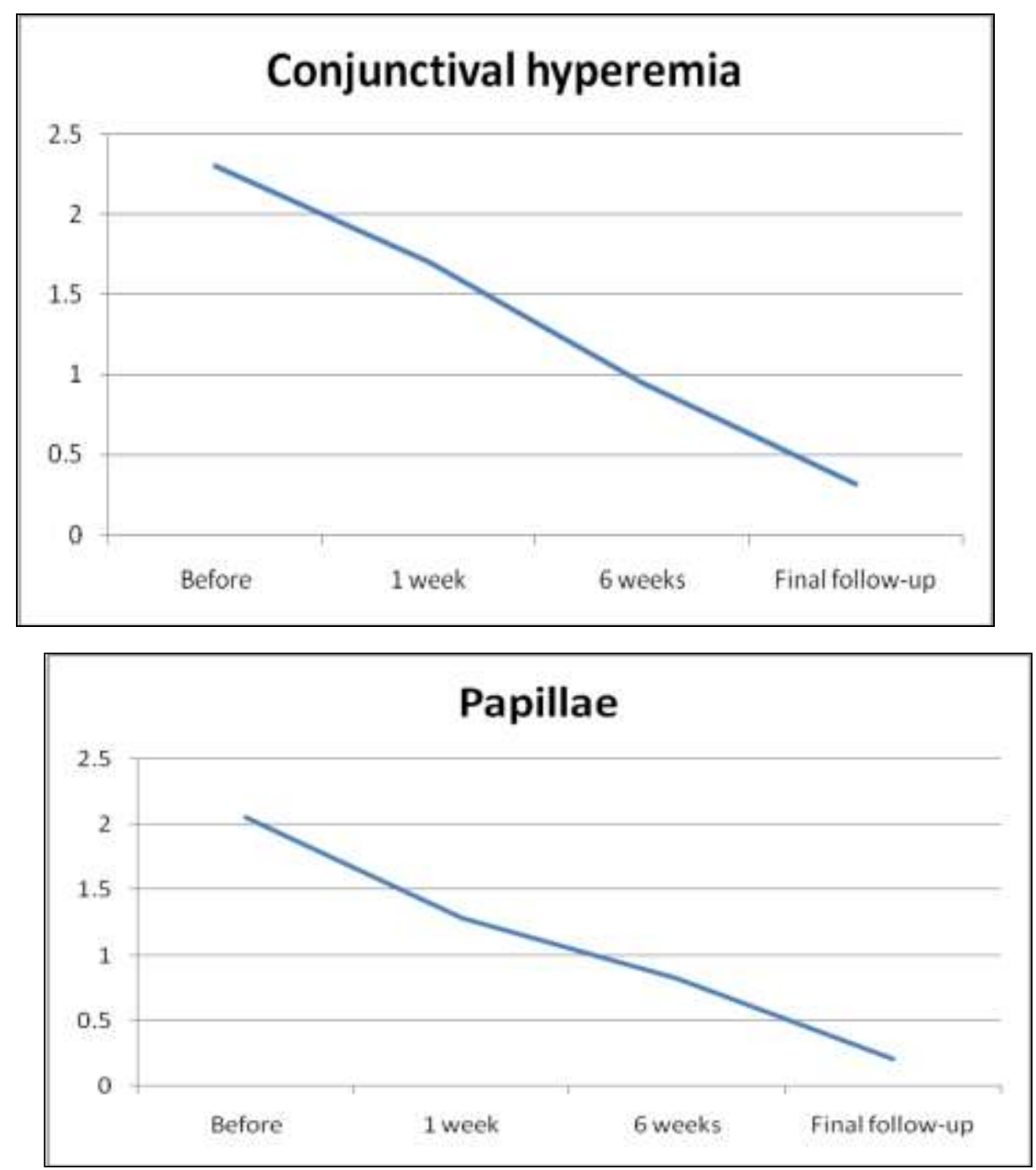

Figure 2c

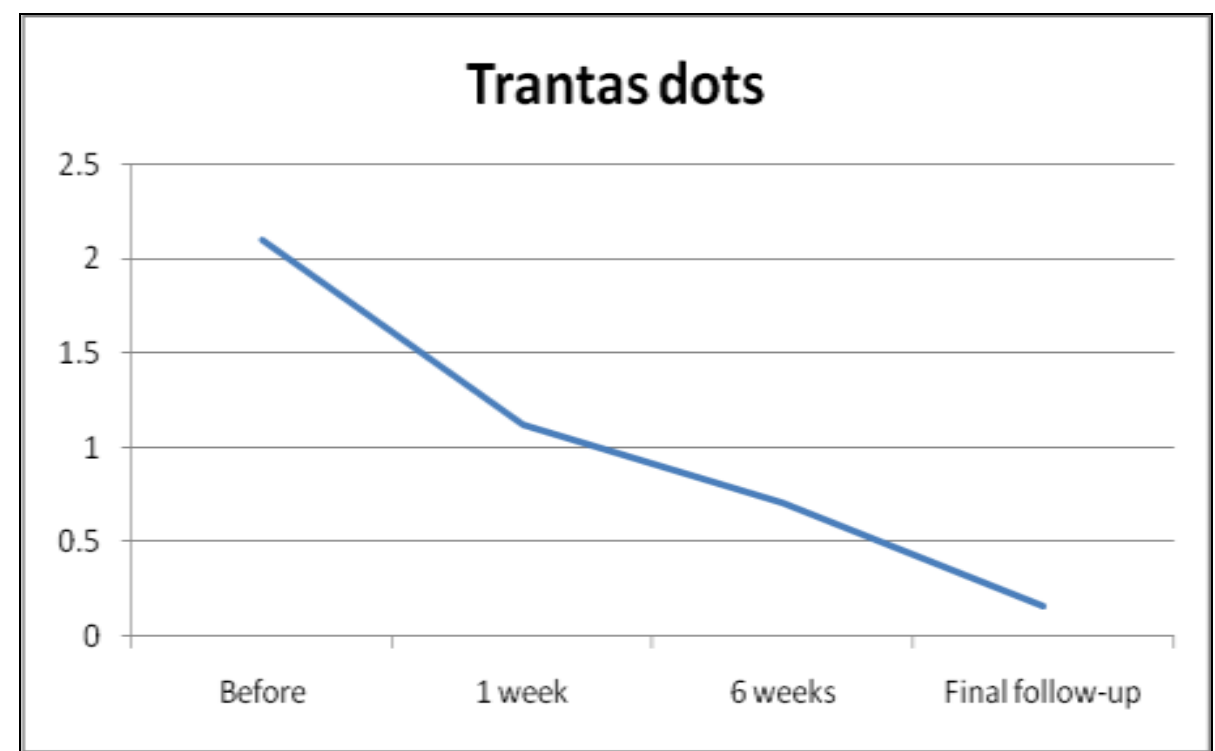

figure 2d 

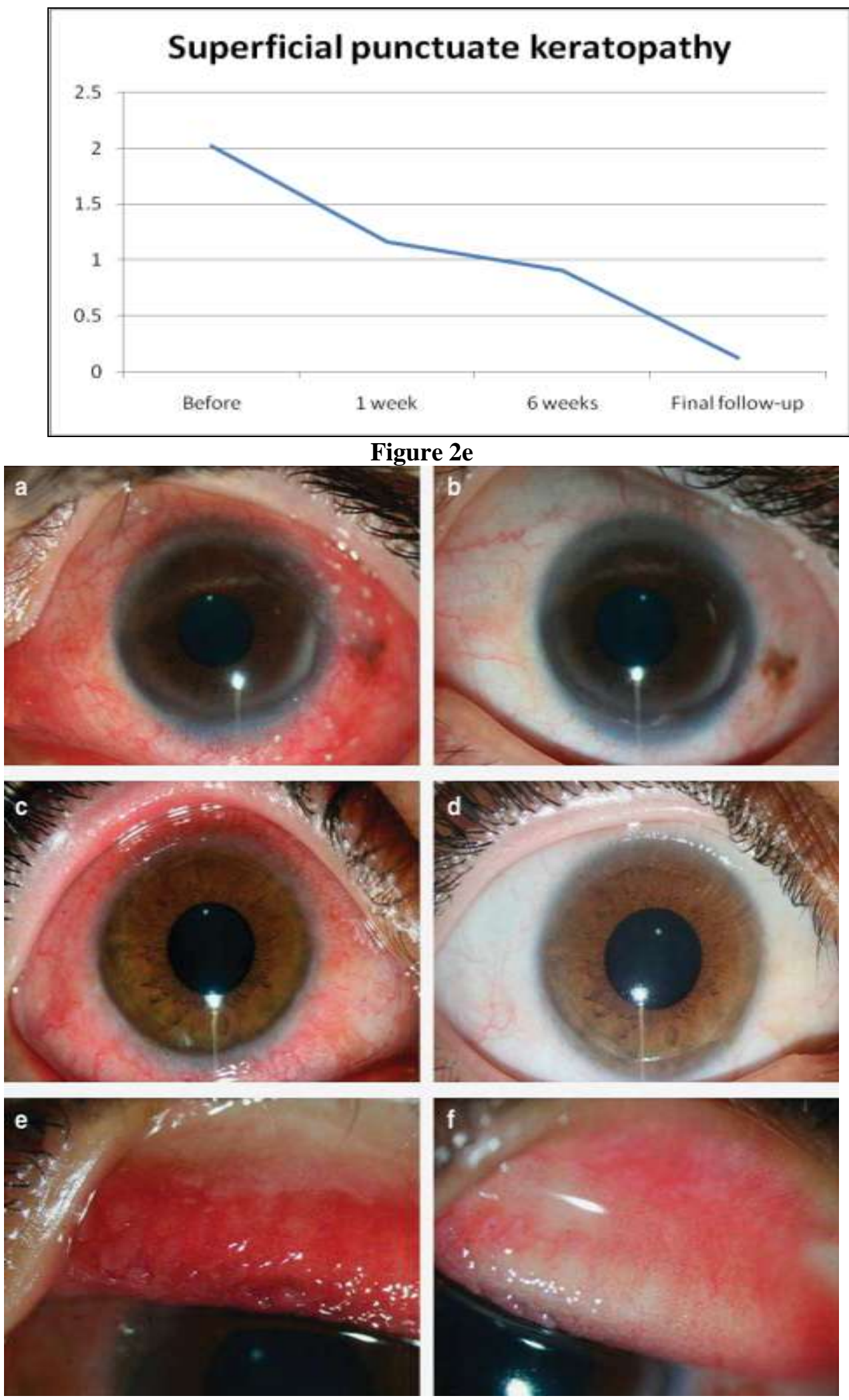

Figure 3: Improvement of conjunctival hyperaemia and conjunctival papillary hypertrophy after treatment with topical $0.1 \%$ tacrolimus eye ointment in refractory VKC. In these two eyes with severe conjunctival hyperaemia (a and c), there was remarkable improvement with mild hyperaemia (b)by 6 weeks or no hyperaemia (d) by 3 month of treatment. This eye with severe conjunctival papillary hypertrophy (e) showed improvement after the treatment (f). 
At the end of the study, all patients with VKC were still using tacrolimus ointment due to recurrence while attempting to discontinue treatment. However, these patients experienced a dramatic improvement when they resumed a once-weekly tacrolimus treatment regimen. Five patients discontinued treatment because of a severe burning sensation and were excluded from the study. BSCVA and refraction remained unchanged throughout the follow-up period.

\section{Discussion}

Tacrolimus is an effective agent for the management of patients with $\mathrm{AKC}$ and $\mathrm{VKC}$ who are refractory to conventional medications, including topical cyclosporine[12-18]. In our study, topical tacrolimus achieved good results in the management of severe cyclosporine-resistant VKC. Previously, Daniell et al[19] reported that $0.05 \%$ topical cyclosporine was not an effective steroid-sparing agent in steroid-dependent allergic conjunctivitis. Consistent with previous reports, almost all patients in our study showed dramatic improvements in inflammatory signs and symptoms without significant adverse effects. Although none of our patients required additional medications, including topical steroids, for additional relief, long-term use of tacrolimus was needed to control disease recurrence. In a multicenter, randomized clinical trial, Ohashi et al[17]. used tacrolimus $0.1 \%$ ophthalmic suspension twice daily for 4 weeks in 21 patients with AKC and 7 patients with VKC and compared to the outcome to a placebo group. They [17]. found the treated eyes showed a marked improvement in symptoms after 4 weeks of treatment.

In our study, all patients completed 24 months of follow-up, and none required additional medications, such as antihistamines, steroids, or mast cell stabilizers, to control disease activity. In the present study, 5 patients were excluded because they were intolerant to the severe burning sensation caused by the application of tacrolimus ointment. This effect may be associated with the activation of herpes simplex dendritic keratitis by the immunosuppressive properties of tacrolimus ointment[16]. However, none of our patients developed herpes simplex keratitis during the long-term follow-up period. The possibility of activation of herpes simplex dendritic keratitis by tacrolimus treatment requires further study. In a clinical study conducted by Sengoku et al. [16] use of tacrolimus $0.1-1 \%$ eye drops achieved a dramatic improvement in the symptoms of patients with refractory VKC. In our study, 20 patients experienced initial mild conjunctival hyperemia (which subsides thereafter) for the first 3 days after initiation of treatment followed by relief of itching [TABLE 4]. When Miyazaki et al [18] used tacrolimus $0.02 \%$ ointment to treat 5 patients with $\mathrm{AKC}$ and 1 patient with VKC who were refractory to conventional treatment; there was a marked improvement in symptoms within 2-4 weeks of treatment.

The symptoms of most of the patients in our study were relieved 4-6 weeks after beginning tacrolimus ointment treatment [TABLE 4]. Allergic symptoms recurred in all patients who attempted to discontinue tacrolimus. Consequently, they were kept on treatment for the entire follow-up period. Although a risk of T-cell lymphoma in patients using topical tacrolimus has been reported,[20] there is insufficient epidemiological evidence to determine if topical calcineurin inhibitors can cause malignancy[21]. Moreover, there is a scarcity of data regarding the optimal dose and duration of treatment. In fact, the blood concentration profiles of patients using tacrolimus $0.1 \%$ ointment were below quantifiable limits $(0.5 \mathrm{ng} / \mathrm{ml})$ in the majority of patients[22].

In our study, no malignancies occurred during the 2 years follow-up period, and the risk of developing malignancy after the application of topical tacrolimus $0.1 \%$ ointment is extremely low. Results from the available literature suggest that tacrolimus skin ointment is a safe and effective treatment for patients with refractory VKC[20]. The small sample size and the lack of randomization and a control group were the main limitations of the current study.

\section{Conclusion}

Tacrolimus, $0.1 \%$ ointment, was effective in controlling the clinical signs and symptoms of severe VKC refractory to topical antihistamine agents and topical cyclosporine. Our results demonstrate that tacrolimus is a promising alternative for the treatment of severe VKC. Further randomized controlled studies are required to evaluate the appropriate concentration and dosage of topical tacrolimus, as well as the long-term systemic safety of this medication.

\section{References}

[1]. Tabbara AK, El-Asrar A. Progress in Allergy and Clinical Immunology. Seattle: Hogrefe and Huber; 1997. Immunopathogenesis of ocular allergy; pp. 381-5.

[2]. Clark AF. Basic sciences in clinical glaucoma:Steroids, ocular hypertension, and glaucoma. J Glaucoma. 1995;4:354-69. [PubMed: 19920699]

[3]. Sacchetti M, Baiardini I, Lambiase A, Aronni S, Fassio O, Gramiccioni C, et al. Development and testing of the quality of life in children with vernal keratoconjunctivitis questionnaire. Am J Ophthalmol. 2007;144:557-63. [PubMed: 17693381]

[4]. Bielory L. Allergic and immunologic disorders of the eye. Part II: Ocular allergy. J Allergy Clin Immunol. 2000;106:101932. [PubMed: 11112882]

[5]. Stahl JL, Barney NP. Ocular allergic disease. Curr Opin Allergy Clin Immunol. 2004;4:455-9. [PubMed: 15349048]

DOI: $10.9790 / 0853-1603062937 \quad$ www.iosrjournals.org $\quad 36 \mid$ Page


[6]. Kino T, Hatanaka H, Hashimoto M, Nishiyama M, Goto T, Okuhara M, et al. FK-506, a novel immunosuppressant isolated from a Streptomyces. I. Fermentation, isolation, and physico-chemical and biological characteristics. J Antibiot (Tokyo) 1987;40:124955. [PubMed: 2445721]

[7]. Sakuma S, Higashi Y, Sato N, Sasakawa T, Sengoku T, Ohkubo Y, et al. Tacrolimus suppressed the production of cytokines involved in atopic dermatitis by direct stimulation of human PBMC system.(Comparison with steroids) Int Immunopharmacol. 2001;1:1219-26. [PubMed: 11407316]

[8]. Zhai J, Gu J, Yuan J, Chen J. Tacrolimus in the treatment of ocular diseases. BioDrugs. 2011;25:89-103. [PubMed: 21443273]

[9]. Kino T, Hatanaka H, Miyata S, Inamura N, Nishiyama M, Yajima T, et al. FK-506, a novel immunosuppressant isolated from a Streptomyces. II. Immunosuppressive effect of FK-506 in vitro. J Antibiot (Tokyo) 1987;40:1256-65. [PubMed: 2445722]

[10]. Sawada S, Suzuki G, Kawase Y, Takaku F. Novel immunosuppressive agent, FK506. In vitro effects on the cloned T cell activation. J Immunol. 1987;139:1797-803.[PubMed: 2442255]

[11]. Ezeamuzie CI. Anti-allergic activity of cyclosporin-A metabolites and their interaction with the parent compound and FK 506. Int J Immunopharmacol. 1996;18:263-70. [PubMed: 8894806]

[12]. Tam PM, Young AL, Cheng LL, Lam PT. Topical tacrolimus $0.03 \%$ monotherapy for vernal keratoconjunctivitis - Case series. Br J Ophthalmol. 2010;94:1405-6.[PubMed: 20558422]

[13]. Mayer K, Reinhard T, Reis A, Böhringer D, Sundmacher R. FK 506 ointment 0.1\% - A new therapeutic option for atopic blepharitis. Clinical trial with 14 patients. Klin Monbl Augenheilkd. 2001;218:733-6. [PubMed: 11731901]

[14]. Kymionis GD, Goldman D, Ide T, Yoo SH. Tacrolimus ointment $0.03 \%$ in the eye for treatment of giant papillary conjunctivitis. Cornea. 2008;27:228-9.[PubMed: 18216583]

[15]. Joseph MA, Kaufman HE, Insler M. Topical tacrolimus ointment for treatment of refractory anterior segment inflammatory disorders. Cornea. 2005;24:417-20.[PubMed: 15829797]

[16]. Sengoku T, Sakuma S, Satoh S, Kishi S, Ogawa T, Ohkubo Y, et al. Effect of FK506 eye drops on late and delayed-type responses in ocular allergy models. Clin Exp Allergy. 2003;33:1555-60. [PubMed: 14616868]

[17]. Ohashi Y, Ebihara N, Fujishima H, Fukushima A, Kumagai N, Nakagawa Y, et al. A randomized, placebo-controlled clinical trial of tacrolimus ophthalmic suspension $0.1 \%$ in severe allergic conjunctivitis. J Ocul Pharmacol Ther. 2010;26:165-74. [PMCID: PMC3158389] [PubMed: 20307214]

[18]. Miyazaki D, Tominaga T, Kakimaru-Hasegawa A, Nagata Y, Hasegawa J, Inoue Y. Therapeutic effects of tacrolimus ointment for refractory ocular surface inflammatory diseases. Ophthalmology. 2008;115:988-92.e5. [PubMed: 17900694]

[19]. Daniell M, Constantinou M, Vu HT, Taylor HR. Randomised controlled trial of topical ciclosporin A in steroid dependent allergic conjunctivitis. Br J Ophthalmol. 2006;90:461-4. [PMCID: PMC1857014] [PubMed: 16547328]

[20]. Hui RL, Lide W, Chan J, Schottinger J, Yoshinaga M, Millares M. Association between exposure to topical tacrolimus or pimecrolimus and cancers. Ann Pharmacother. 2009;43:1956-63. [PubMed: 19903860]

[21]. Tennis P, Gelfand JM, Rothman KJ. Evaluation of cancer risk related to atopic dermatitis and use of topical calcineurin inhibitors. Br J Dermatol. 2011;165:465-73.[PubMed: 21466537]

[22]. Ebihara N, Ohashi Y, Fujishima H, Fukushima A, Nakagawa Y, Namba K, et al. Blood level of tacrolimus in patients with severe allergic conjunctivitis treated by $0.1 \%$ tacrolimus ophthalmic suspension. Allergol Int. 2012;61:275-82. [PubMed: 22361511]

[23]. Ohji M, Kinoshita S, Ohmi E, Kuwayama Y. Marked intraocular pressure response to instillation of corticosteroids in children. Am J Ophthalmol. 1991;112:450-454.

[24]. Rallis E, Korfitis C, Gregoriou S, Rigopoulos D. Assigning new roles to topical tacrolimus. Expert Opin Investig Drugs. 2007;16(8):1267-1276. 